\title{
KAJIAN SERAPAN PADA BETON RINGAN MEMADAT MANDIRI MENGGUNAKAN AGREGAT KASAR PECAHAN GENTENG DENGAN VARIASI KADAR VISCOCRETE
}

\author{
Bimo Yoga Pratama ${ }^{1)}$, Antonius Mediyanto ${ }^{2)}$, Endang Rismunarsi ${ }^{3)}$ \\ 1) Mahasiswa Program Studi Teknik Sipil Fakultas Teknik Universitas Sebelas Maret \\ 2) Dosen Program Studi Teknik Sipil Fakultas Teknik Universitas Sebelas Maret \\ 3) Dosen Program Studi Teknik Sipil Fakultas Teknik Universitas Sebelas Maret \\ Jl. Ir. Sutami 36 A, Kentingan, Surakarta, 57126, Telp (021) 647069, Fax 662118
}

Email: bimoyp@gmail.com

\begin{abstract}
Lightweight Self Compacting Concrete is one of the most recent developments in concrete technology. This concrete contains lightweight aggregate (either natural or artificial) and does not require a vibratory compactor during the compaction process. Natural lightweight aggregates can be made from pumice, scoria, or tuff. On the other hand, artificial aggregates are made by heating various materials: clay, light ash, slate ash, and claystone. A Viscocrete-type superplasticizer was added to improve the workability of this lightweight concrete so that fresh concrete can flow easily and solidify itself. This study examined the water absorption due to the variation of Viscocrete superplasticizer utilization. Viscocrete was employed at a concentration of $1.5 \%, 1.75 \%, 2 \%$ and $2.25 \%$ of the cement content. The absorption test was conducted using cylindrical specimens with a diameter of $7.5 \mathrm{~cm}$ and a height of $15 \mathrm{~cm}$ following SNI 03-2914-1992.
\end{abstract}

Keywords: Lightweight aggregate, Lightweight Self Compacting Concrete, Viscocrete, W ater absorption, Workability

\begin{abstract}
Abstrak
Teknologi beton selalu mengalami perkembangan yang lebih dinamis, beton ringan memadat mandiri (Lightweight Self Compacting ( Concrete) adalah salah satu beton yang dikembangkan. Beton ini terbuat dari agregat ringan yang dalam proses pemadatannya tidak membutuhkan alat penggetar (vibrator). Agregat ringan alami yaitu agregat yang diperoleh dari bahan-bahan alami seperti batu apung, skoria, atau tufa. Sedangkan agregat buatan adalah agregat yang dibuat melalui proses pemanasan seperti tanah liat, abut terang, abu sabak, dan batu lempung. Untuk meningkatkan workability pada beton ringan ini, maka digunakan penambahan superplasticizer jenis Viscocrete sehingga diharapkan beton segar mudah mengalir dan melakukan pemadatan mandiri. Penelitian ini mengamati serapan akibat penambahan kadar Viscocrete. Kadar Viscocrete yang digunakan ialah 1,5\%; 1,75\%; $2 \%$; dan 2,25\%. Benda uji yang digunakan untuk pengujian serapan adalah silinder berukuran diameter 7,5 cm dan tinggi 15 $\mathrm{cm}$.
\end{abstract}

Kata Kunci: Agregat ringan, Beton Ringan Memadat Mandiri, Serapan, Viscocrete, workabilitas

\section{PENDAHULUAN}

Teknologi beton selalu mengalami perkembangan yang dinamis, khususnya Self Compacting Concrete (SCC). Teknologi dikembangkan salah satunya adalah Light-weight Self Compacting Concrete (LSCC).

Beton ringan merupakan beton yang memiliki berat jenis yang lebih kecil dibandingkan dengan beton normal pada umumnya. Beton ringan digunakan untuk mengurangi beban mati suatu struktur beton. Beton beragregat ringan adalah beton yang memiliki struktur tertutup dan kepadatan tidak lebih dari $2200 \mathrm{~kg} / \mathrm{m}^{3}$ untuk beton bertulang dan memiliki struktur tertutup dan kepadatan tidak lebih dari $2000 \mathrm{~kg} / \mathrm{m}^{3}$ untuk beton polos (Eurocode 2-2004).

Beton ringan dapat dibuat dengan menggunakan agregat kasar yang lebih ringan dari kerikil. Dalam penelitian ini, agregat kasar yang digunakan adalah pecahan genteng. Jenisnya berupa sokka dengan spesifikasi lolos ayakan 12,5 mm dan tertahan $9,5 \mathrm{~mm}$.

Beton ini dituntut memiliki workability yang tinggi dengan menambahkan superplasticizer. Superplasticizer mampu membuat pasta bergerak bebas mengisi pori-pori beton. Dalam penelitian ini superplasticizer yang digunakan adalah tipe Sika Viscocrete 8050SG. Bahan viscocrete digunakan untuk mereduksi air dan meningkatkan workability pada beton serta mencegah terlepasnya semen dan material halus lainnya pada saat beton segar berada ada tahap pengerasan. 
Salah satu yang menentukan beton yang baik adaah beton yang relatif tidak bisa dilewati air/gas atau dengan kata lain memiliki permeabilitas yang rendah. Serapan beton berpengaruh terhadap durabilitas dari beton itu sendiri. Untuk itu maka dilakukan penelitian untuk mengetahui nilai serapan dari beton.

\section{Serapan}

Serapan air adalah kemampuan beton untuk menyerap air. Serapan air ini dapat menentukan banyaknya pori yang terkandung di dalam beton. Semakin berat nilai presentase serapan air, maka kandungan pori yang ada ada beton tersebut semakin banyak. Metode yang digunakan untuk menguji serapan beton adalah tes pengujian serapan langsung dengan variasi waktu.

\section{METODE PENELITIAN}

Metode penelitian yang digunakan pada penelitian ini ialah metode eksperimental untuk mengkaji serapan yang dilakukan di Laboratorium Struktur Fakultas Teknik Universitas Sebelas Maret. Pengujian serapan dilakukan pada beton silinder berukuran diameter 7,5 cm dan tinggi $15 \mathrm{~cm}$ dengan umur 28 hari. Variasi kadar VSiscocrete yang digunakan pada tiap pengujian adalah $1,5 \% ; 1,75 \% ; 2 \%$; dan 2,25\%. Tiap variasi masing-masing pengujian terdiri dari 3 sampel. Selanjutnya data hasil pengujian tersebut akan diolah menggunakan Microsoft Excel.

Tabel 1. Nama dan jumlah benda uji

\begin{tabular}{llll}
\hline $\begin{array}{l}\text { Kadar Vis- } \\
\text { cocrete }\end{array}$ & $\begin{array}{l}\text { Nama } \\
\text { Benda Uji }\end{array}$ & $\begin{array}{l}\text { Umur } \\
\text { (hari) }\end{array}$ & Jumlah \\
\hline $1,5 \%$ & VC 1,50 & 28 & 3 \\
$1,75 \%$ & VC 1,75 & 28 & 3 \\
$2 \%$ & VC 2,00 & 28 & 3 \\
$2,25 \%$ & VC 2,25 & 28 & 3 \\
\hline \multicolumn{5}{r}{ TOTAL BENDA UJI } & $\mathbf{1 2}$ \\
\hline
\end{tabular}

Rumus perhitungan serapan air:

$$
\text { SerapanAir }=\frac{W-W_{k}}{W_{k}} \times 100 \%
$$

Keterangan:

$\mathrm{W}=$ Berat beton pada kondisi SSD (kering permukaan)

$\mathrm{Wk} \quad=$ Berat beton pada kondisi kering oven

\section{HASIL DAN PEMBAHASAN}

\section{Mix Design}

Rancangan campuran adukan beton ringan memadat mandiri dengan agregat kasar pecahan genteng dengan variasi kadar viscocrete berdasarkan EFNARC 2005.

Tabel 2. Mix Design

\begin{tabular}{|c|c|c|c|c|c|}
\hline Benda Uji & $\begin{array}{l}\text { Agg. Halus } \\
\left(\mathrm{kg} / \mathrm{m}^{3}\right)\end{array}$ & $\begin{array}{l}\text { Agg. Kasar } \\
\left(\mathrm{kg} / \mathrm{m}^{3}\right)\end{array}$ & $\begin{array}{l}\text { Semen } \\
\left(\mathrm{kg} / \mathrm{m}^{3}\right)\end{array}$ & $\begin{array}{l}\text { Viscocrete } \\
\left(1 \mathrm{lt} / \mathrm{m}^{3}\right)\end{array}$ & $\begin{array}{l}\text { Air } \\
\left(1 \mathrm{lt} / \mathrm{m}^{3}\right)\end{array}$ \\
\hline LSCC-KL-V 1,5 & 897,56 & 557,70 & 500 & 7,5 & 162,5 \\
\hline LSCC-KL-V 1,75 & 897,56 & 557,70 & 500 & 8,75 & 162,5 \\
\hline LSCC-KL-V 2 & 897,56 & 557,70 & 500 & 10 & 162,5 \\
\hline LSCC-KL-V 2,25 & 897,56 & 557,70 & 500 & 11,25 & 162,5 \\
\hline
\end{tabular}




\section{Hasil Pengujian Beton Segar}

Hasil pengujian beton segar dapat dilihat pada tabel 3-5.

Tabel 3. Hasil pengujian Slump Flow

\begin{tabular}{|c|c|c|c|c|c|c|c|c|}
\hline \multirow{3}{*}{ Kode } & \multicolumn{5}{|c|}{ Flow Table Test } & \multirow{2}{*}{\multicolumn{3}{|c|}{$\begin{array}{l}\text { Syarat Menurut } \\
\text { EFNARC }\end{array}$}} \\
\hline & \multicolumn{4}{|c|}{ Diameter } & \multirow{2}{*}{$\begin{array}{l}\text { Waktu } \\
t_{500} \\
\text { (dt) }\end{array}$} & & & \\
\hline & $\begin{array}{l}\mathrm{d} 1 \\
(\mathrm{~mm})\end{array}$ & $\begin{array}{l}\mathrm{d} 2 \\
(\mathrm{~mm})\end{array}$ & $\begin{array}{l}\mathrm{d} 3 \\
(\mathrm{~mm})\end{array}$ & $\begin{array}{l}d_{\text {rata-rata }} \\
(\mathrm{mm})\end{array}$ & & $\begin{array}{l}T_{500} \\
\text { (s) }\end{array}$ & $\begin{array}{l}d_{\text {rata-rata }} \\
(\mathrm{mm})\end{array}$ & Keterangan \\
\hline Viscocrete-1,5 & 630 & 630 & 640 & 633,33 & 3,29 & $2-5$ & $650-800$ & $\mathrm{X}$ \\
\hline Viscocrete-1,75 & 640 & 640 & 660 & 646,67 & 3,09 & $2-5$ & $650-800$ & $\mathrm{X}$ \\
\hline Viscocrete-2 & 700 & 710 & 710 & 706,67 & 2,57 & $2-5$ & $650-800$ & V \\
\hline Viscocrete-2,25 & 700 & 700 & 740 & 713,33 & 2,15 & $2-5$ & $650-800$ & $\mathrm{~V}$ \\
\hline
\end{tabular}

Keterangan: $\mathrm{V}=$ Memenuhi syarat

Tabel 4. Hasil pengujian L-Box

\begin{tabular}{lllllc}
\hline \multirow{2}{*}{ Kode } & \multicolumn{5}{c}{ L-Box Type } \\
\cline { 2 - 6 } & $\begin{array}{l}\mathbf{h} \mathbf{1} \\
\mathbf{( m m )}\end{array}$ & $\begin{array}{l}\mathbf{h} \mathbf{( m m )} \\
\mathbf{( m m}\end{array}$ & $\mathbf{h} \mathbf{2} \mathbf{h} \mathbf{1}$ & $\begin{array}{l}\text { Syarat } \\
\mathbf{( h 2 / h 1 )}\end{array}$ & Keterangan \\
\hline Viscocrete-1,5 & 7,2 & 10 & 0,72 & $0,8-1$ & $\mathrm{X}$ \\
Viscocrete-1,75 & 7 & 9 & 0,78 & $0,8-1$ & $\mathrm{X}$ \\
Viscocrete-2 & 6,3 & 6,9 & 0,91 & $0,8-1$ & $\mathrm{~V}$ \\
Viscocrete-2,25 & 6,2 & 6,5 & 0,95 & $0,8-1$ & $\mathrm{~V}$ \\
\hline
\end{tabular}

Keterangan: $\mathrm{V}=$ Memenuhi syarat

Tabel 5. Hasil pengujian $V$-funnel

\begin{tabular}{llllc}
\hline Kode & $\begin{array}{l}\mathbf{T} \\
(\mathbf{d t})\end{array}$ & $\begin{array}{l}\mathbf{T}_{5} \\
(\mathbf{d t})\end{array}$ & $\begin{array}{l}\text { Syarat } \\
(\mathbf{d t})\end{array}$ & Keterangan \\
\hline Viscocrete-1,5 & 16,89 & 19,94 & $6-12$ & $\mathrm{X}$ \\
Viscocrete-1,75 & 15,51 & 18,78 & $6-12$ & $\mathrm{X}$ \\
Viscocrete-2 & 9,17 & 12,68 & $6-12$ & $\mathrm{X}$ \\
Viscocrete-2,25 & 8,07 & 11,01 & $6-12$ & $\mathrm{~V}$ \\
\hline
\end{tabular}

Keterangan: $\mathrm{V}=$ Memenuhi syarat

\section{Hasil Pengujian Berat Volume}

Berat volume beton bergantung pada berat volume bahan penyusun beton tersebut. Pengujian berat volume atau berat jenis beton untuk mengetahui berat jenis masing-masing benda uji. Hasil pengujian dapat dilihat pada Tabel 6.

Tabel 6. Hasil pengujian berat volume beton rata-rata

\begin{tabular}{llll}
\hline Nama Sampel & $\begin{array}{l}\text { Volume } \\
\mathbf{( m}^{\mathbf{3}} \mathbf{)}\end{array}$ & $\begin{array}{l}\text { Berat } \\
\mathbf{( k g )}\end{array}$ & $\begin{array}{l}\text { Berat Volume } \\
\mathbf{( k g / \mathbf { m } ^ { 3 } )}\end{array}$ \\
\hline LSCC VC 1,5 & 0,0053 & 10,7605 & 2018 \\
LSCC VC 1,75 & 0,0053 & 10,5820 & 2037 \\
LSCC VC 2 & 0,0053 & 10,6700 & 2026 \\
LSCC VC 2,25 & 0,0053 & 10,6200 & 2016 \\
\hline
\end{tabular}

\section{Hasil Pengujian Serapan}

Pengujian serapan beton dilakukan pada beton silinder dengan diameter 7,5 cm dan tinggi $15 \mathrm{~cm}$ dengan umur beton 28 hari. Pengujian ini dilakukan dengan menggunakan alat pengujian serapan. Hasil pengujian dapat dilihat pada Tabel 7. 
Tabel 7. Hasil pengujian serapan

\begin{tabular}{|c|c|c|c|c|c|}
\hline \multirow{2}{*}{ Nama Sampel } & \multicolumn{2}{|c|}{ Nilai Serapan Air Rerata (\%) } & \multicolumn{2}{|c|}{ Syarat SNI 03-2914-1992 (\%) } & \multirow[t]{2}{*}{ Keterangan } \\
\hline & $10+0,5$ menit & $1 \times 24$ jam & $10+0,5$ menit & $1 \times 24$ jam & \\
\hline VC 1,5 & 0,28 & 4,36 & $<2,5$ & $<6,5$ & $\mathrm{~V}$ \\
\hline VC 1,75 & 0,27 & 3,97 & $<2,5$ & $<6,5$ & $\mathrm{~V}$ \\
\hline VC 2 & 0,25 & 3,49 & $<2,5$ & $<6,5$ & $\mathrm{~V}$ \\
\hline VC 2,25 & 0,05 & 0,67 & $<2,5$ & $<6,5$ & $\mathrm{~V}$ \\
\hline
\end{tabular}

Keterangan:

$\mathrm{V}=$ Memenuhi syarat

\section{SIMPULAN}

Dari hasil penelitian dan pembahasan yang telah diuraikan, dapat ditarik kesimpulan sebagai berikut:

1. Semua beton yang dibuat pada penelitian ini mendekati standar Lightweight Self Compacting Concrete (LSCC) dengan berat jenis rata-rata $2037 \mathrm{~kg} / \mathrm{m}^{3}$.

2. Besar nilai persentase serapan air untuk perendaman $10+0,5$ menit berturut-turut dengan kadar 1,5\%, 1,75\%, $2 \%, 2,25 \%$ adalah $0,28 \%, 0,27 \%, 0,25 \%$, dan 0,05\%, sehingga memenuhi syarat SNI 03-2914-1992 untuk beton kedap air normal dengan batas maksimum sebesar $2,5 \%$.

3. Besar nilai persentase serapan air untuk perendaman 1x24 jam berturut-turut dengan kadar 1,5\%, 1,75\%, 2\%, dan $2,25 \%$ adalah $4,36 \%, 3,97 \%, 3,49 \%$, dan 0,67\%, sehingga memenuhi syarat SNI 03-2914-1992 untuk beton kedap air normal dengan batas maksimum sebesar 6,5\%.

4. Penambahan kadar Viscocrete dapat mengurangi nilai serapan.

\section{SARAN}

Beberapa pembetulan perlu dilakukan terhadap penelitian ini agar penelitian selanjutnya menjadi lebih baik. Saransaran untuk penelitian selanjutnya adalah:

1. Membuat benda uji lebih dari yang dibutuhkan, sehingga hasil yang didapatkan menjadi akurat dan terdapat cadangan ketika terdapat benda uji yang tidak dapat digunakan.

2. Perhatikan cetakan benda uji agar beton tidak mengalami kemiringan, karena bentuk dari beton berpengaruh terhadap penilitan.

3. Penelitian lebih lanjut terhadap variasi kadar bahan tambah jenis Viscocrete agar hasil penelitian lebih baik.

\section{REFERENSI}

Association of Standard Testing Materials, 2006, "ASTM C494: Standard Specification for Chemical Admixture for Concrete”, United States.

Astiqomah, Yuli., 2019, "Kajian Parameter Beton Ringan Memadat Mandiri Menggunakan Agregat Kasar Pecahan Genteng dengan Variasi Bahan Tambah Superplasticizer Tipe Viscocrete-8050SG", Universitas Sebelas Maret, Surakarta.

Dipohusodo, I., 1999, “Struktur Beton Bertulang”, Gramedia Pustaka Utama. Jakarta.

Eurocode 2. 2004, "Desain of Concrete Structures, Part 1-1", The European Union.

EFNARC., 2005, "The European Guidelines for Self-Compacting Concrete".

Murdock, L. J. dan Brook. K. M. dan S. Hendarko., 1979, “Bahan dan Praktek Beton”, Erlangga. Jakarta. 